University of Nebraska - Lincoln

DigitalCommons@University of Nebraska - Lincoln

Faculty Publications from the Harold W. Manter

Laboratory of Parasitology

Parasitology, Harold W. Manter Laboratory of

2009

\title{
The Identification of Cattle Nematode Parasites Resistant to Multiple Classes of Anthelmintics in a Commercial Cattle Population in the US
}

\author{
Louis C. Gasbarre \\ Bovine Functional Genomics Laboratory, ARS, United States Department of Agriculture, \\ Igasbarr@anri.barc.usda.gov \\ Larry L. Smith \\ Larry L. Smith Research and Development, Inc. \\ J. Ralph Lichtenfels \\ Animal Parasitic Disease Lab, ARS, United States Department of Agriculture, 2jrcgl@gmail.com \\ Patricia A. Pilitt \\ Animal Parasitic Disease Lab, ARS, United States Department of Agriculture, ppilitt@anri.barc.usda.gov
}

Follow this and additional works at: https://digitalcommons.unl.edu/parasitologyfacpubs

Part of the Parasitology Commons

Gasbarre, Louis C.; Smith, Larry L.; Lichtenfels, J. Ralph; and Pilitt, Patricia A., "The Identification of Cattle Nematode Parasites Resistant to Multiple Classes of Anthelmintics in a Commercial Cattle Population in the US" (2009). Faculty Publications from the Harold W. Manter Laboratory of Parasitology. 625.

https://digitalcommons.unl.edu/parasitologyfacpubs/625

This Article is brought to you for free and open access by the Parasitology, Harold W. Manter Laboratory of at DigitalCommons@University of Nebraska - Lincoln. It has been accepted for inclusion in Faculty Publications from the Harold W. Manter Laboratory of Parasitology by an authorized administrator of DigitalCommons@University of Nebraska - Lincoln. 


\title{
The identification of cattle nematode parasites resistant to multiple classes of anthelmintics in a commercial cattle population in the US
}

\author{
Louis C. Gasbarre ${ }^{\mathrm{a}, *}$, Larry L. Smith ${ }^{\mathrm{b}}$, J. Ralph Lichtenfels ${ }^{\mathrm{c}}$, Patricia A. Pilitt ${ }^{\mathrm{c}}$ \\ ${ }^{a}$ Bovine Functional Genomics Laboratory, ARS, USDA, Building 200, Rm 6, BARC-East, Beltsville, MD 20705, United States \\ ${ }^{\mathrm{b}}$ Larry L. Smith Research and Development, Inc., Lodi, WI, United States \\ ${ }^{\mathrm{c}}$ Animal Parasitic Disease Lab, ARS, USDA, Beltsville, MD, United States
}

\section{A R T I C L E I N F O}

\section{Article history:}

Received 2 June 2009

Received in revised form 13 August 2009

Accepted 15 August 2009

\section{Keywords:}

Cattle

Drug resistance

Anthelmintic

Nematodes

\begin{abstract}
A B S T R A C T
Resistance to modern anthelmintics by ruminant nematode parasites is an increasing problem throughout the world. To date the problem has largely been reported in parasites of small ruminants, but there are increasing reports of such resistance in nematodes recovered from cattle. Until now there have been no published reports of drug resistant parasites from cattle in North America. In 2002 a producer in the upper Midwest who backgrounds young cattle acquired from the southeastern US experienced lower than expected weight gain as well as apparent parasitic gastroenteritis in his cattle during the fall. Fecal sample results supported the suspicion that decreased productivity and diarrhea were the result of GI nematode parasitism. The operation used intensive grazing management and practiced strategically timed deworming for $>17$ year. In 2003, all animals were dewormed the first week of May with Ivomec Plus ${ }^{\mathbb{R}}$, then with Dectomax ${ }^{\mathbb{R}}$ Injectable on 4 June and 17 July. On 31 July, 10 randomly taken fecal samples showed EPG values from 0 to 55 . To assess whether the apparent decreased drug efficacy was the result of drug resistance in the nematode population, on 18 August approximately 150 heads, previously strategic timed dewormed, of 9-11 month old cattle from one pasture were selected for study. The calves were randomly assigned to 1 of 6 treatment groups: untreated $(\mathrm{U})$, ivermectin injectable $(\mathrm{I})$, moxidectin pour-on $(\mathrm{M})$, doramectin injectable (D), eprinomectin pour-on (E), albendazole oral (A). Cattle were weighed prior to treatment and the drug was dosed according to label directions. Seven days later, 3 calves from each group were slaughtered for worm recovery. Fecal samples taken from the remaining animals at 14 days after treatment showed that the reduction of mean fecal EPG value for each group was: U-46\%, I-52\%, M-72\%, D-61\%, E-8\%, and A-68\%. Worm recovery from the slaughter calves showed that all groups harbored significant numbers of Haemonchus placei and $H$. contortus. In addition, all avermectin-treated groups contained significant numbers of Cooperia punctata, and smaller numbers of $C$. oncophora and $C$. spatulata. These results imply that the pastures studied contain substantial numbers of $H$. contortus resistant to both avermectins and benzimidazoles, and H. placei and Cooperia sp. resistant to all the commonly used avermectin anthelmintics. This is the first report of anthelmintic resistance in American cattle parasites.
\end{abstract}

(c) 2009 Published by Elsevier B.V.

\footnotetext{
* Corresponding author. Tel.: +1 301504 8509; fax: +1 3015046426.

E-mail address: lgasbarr@anri.barc.usda.gov (L.C. Gasbarre).
}

\section{Introduction}

The discovery of the avermectin anthelmintics has had a profound influence on livestock production in the US. Their large margins of safety, high efficacy and broad range of activity have influenced both the manner and frequency 
in which anthelmintics are used, as well as livestock raising practices. Coinciding with the advent of the avermectins has been the development of strategic treatment regimens which have had as their target optimal animal productivity through the reduction of parasite transmission resulting from clearing pastures of infectious larvae. The combination of highly efficacious, broad spectrum drugs with treatment programs that apply the drugs in such a way to maximize reductions in the parasite populations has led to a number of alterations in production practices including higher stocking rates and reductions in the use of alternative control practices.

While these programs have proven to be profitable for many cattle raisers in the US, there has been concern that programs which rely strictly upon drug administration without regard for good pasture parasite management will lead to more rapid selection of drug resistance in the nematode populations. This has been well documented in small ruminant species, in which GI nematodes resistant to all classes of anthelmintics have been well documented (see Waller, 1997). The scarcity of well documented reports of drug resistance in cattle nematodes, has led to the suggestion that because the immune system of cattle seems to handle GI nematode infections better than those of sheep and goats, anthelmintic resistance in cattle parasites was unlikely to arise due to lower selective pressure because of lower drug usage (Waller, 1994). While this idea has been broadly held, there have been increasing anecdotal reports of lowered anthelmintic efficacy in cattle, and well documented reports of drug resistance to benzimidazoles by Cooperia sp. in New Zealand (Vermunt et al., 1995; Hosking et al., 1996), to ivermectin by Cooperia sp. in Great Britain (Stafford and Coles, 1999), and to both macrocyclic lactones and benzimidazoles by Haemonchus sp. and to the macrocyclic lactones by Cooperia sp. in Argentina (Anziani et al., 2004).

To date, no such parasites have been reported from North America. Here we describe studies that demonstrate resistance to all the commonly used avermectins and moxidectin by Cooperia sp. and Haemonchus sp. and to the benzimidazoles by Haemonchus contortus in cattle.

\section{Materials and methods}

\subsection{History of animals}

Female or castrated male beef or beef cross calves used for this study were purchased in the winter of 2002-2003 by order-buyers at auction barns in the southeastern United States at a weight of $80-100 \mathrm{~kg}$. Upon assembly, they were dewormed with Dectomax ${ }^{\mathbb{R}}$ Injectable, and then placed with various contract grazers in Alabama and Mississippi. While on pasture, the animals were dewormed once or twice with either Ivomec ${ }^{\circledR}$ or Cydectin ${ }^{\circledR}$. During the first week of May 2003, animals were re-assembled from the grazers, sorted according to weight, and dewormed with Ivomec Plus $^{\circledR}$ Injectable, after which they were shipped to Wisconsin. There, the 152 lightest animals were placed on the pasture used in this study for the summer 2003.

The pasture forage used for grazing was primarily bluegrass with red and white clover. An oat by-product (oat hulls), corn screenings and a salt-mineral containing Rumensin ${ }^{\mathbb{R}}$ were available free choice.

\subsection{History of pasture}

Only cattle had been grazed on this pasture for the previous 40 year. Since approximately 1980, all animals grazed on this pasture had been dewormed at turnout with either fenbendazole or one of the avermectins, then strategically twice more during the grazing season. Dectomax $^{\circledR}$ Injectable was used to deworm all animals on 4 June and 17 July 2003. On 31 July 2003, 10 fecal samples were taken randomly; the EPG range was 0-55. The results indicated the possible presence of gastrointestinal parasites resistant to the anthelmintics used.

\subsection{Fecal sampling and animal identification}

A new plastic sleeve was used on each of 150 of the 152 animals on this pasture to obtain rectal fecal samples on 18 August 2003. A uniquely numbered ear tag was also placed in one ear of each animal. On 10 September 2003, 14 days after treatment (Coles et al., 1992), fecal samples were taken from remaining animals on the pasture for a fecal egg reduction test using the same procedure.

\subsection{Fecal examination}

A modified Wisconsin technique was used in which $5.0 \mathrm{~g}$ feces were mixed with a small amount of tap water. The mixture was screened through a coarse sieve, poured into a $15 \mathrm{ml}$ centrifuge tube, and spun at $1 \times 10^{3} \mathrm{rpm}$ for $10 \mathrm{~min}$. The supernatant was discarded; $12 \mathrm{ml}$ of concentrated sugar solution (1200 g sugar/I $400 \mathrm{ml}$ distilled water $/ 2 \mathrm{~g}$ phenol) was added, and then mixed to break up the pellet. More sugar solution was added to form a convex meniscus. A cover slip was placed on the meniscus and the tube centrifuged again at $1000 \mathrm{rpm}$ for $10 \mathrm{~min}$, or allowed to stand for $30 \mathrm{~min}$. The cover slip to which the eggs adhered was removed from the tube and placed on a microscope slide. The ova counts were divided by 5 and reported as eggs per gram.

\subsection{Allocation to treatment}

The animals were ranked from highest to lowest EPG. Based on decreasing EPG counts, replicates of 6 animals were formed. Within each replicate, drawing numbers from a container randomly assigned animals to treatment. The study was designed to have a minimum of 24 animals per treatment group.

Each of the anthelmintics constituted a treatment group:

$\begin{array}{lll}\text { Ivermectin (Ivomec }{ }^{\mathbb{R}} \text { Injectable) } & \text { Lot KBC055 } & \text { Exp. 10/2004 } \\ \text { Eprinomectin (Eprinex Pour-on }^{\mathbb{R}} \text { ) } & \text { Lot LBJ 1100 } & \text { Exp. 05/2004 } \\ \text { Doramectin (Dectomax }{ }^{\mathbb{B}} \text { Injectable) } & \text { Lot K2D0032 } & \text { Exp. 2005 } \\ \text { Moxidectin }\left(\text { Cydectin Pour-on }^{\mathbb{R}} \text { ) }\right. & \text { Lot 268774 } & \text { Exp. 04/2006 } \\ \text { Albendazole }\left(\text { Valbazen }^{\mathbb{R}} \text { ) }\right. & \text { Lot 2311021 } & \text { Exp. 08/2004 }\end{array}$

No medication to control group

Animals were individually weighed before treatment on a Tru-Test ${ }^{\circledR}$ scale on 27 August 2003. 
Certified weights were used to check the scale for accuracy before the first and after the last animal was weighed. The weight range was $117-307 \mathrm{~kg}$.

One individual calculated dose according to the specifications of the manufacturer; another individual did the same and confirmed the calculation before dosing. Injectable products (ivermectin and doramectin) were injected subcutaneously in the neck area with a 16 guage- 1 in. Monoject ${ }^{\circledR}$ needle attached to a $12 \mathrm{cc}$ syringe accurate to $0.2 \mathrm{ml}$. The calculated dose was rounded up to the next $0.2 \mathrm{ml}$. A new syringe and needle were used on each animal. Pour-on products (eprinomectin and moxidectin) were poured from the withers to the tailhead using a $35 \mathrm{ml}$ Monoject ${ }^{\circledR}$ syringe accurate to $1 \mathrm{ml}$. The calculated dose was rounded up to the next milliliter. Albendazole was administered orally using a $35 \mathrm{ml}$ Monoject $^{\mathbb{B}}$ syringe accurate to $1 \mathrm{ml}$. The calculated dose was rounded up to the next milliliter.

Control animals were processed as the treated animals, but without drug treatment.

\subsection{Selection of animals for necropsy}

Three replicates of 6 animals per replicate were selected for necropsy, removed from the pasture 4 days after treatment and placed in a concrete floored pen until necropsy 7 days after treatment. The goal was to select one replicate above the mean EPG average, one replicate near the EPG mean, and one replicate with an EPG mean average below the mean (Table 1 ).

\subsection{Nematode identification}

Nematodes were cleared in phenol-alcohol (80 parts melted phenol crystals and 20 parts absolute ethanol) for

Table 1

Fecal egg per gram (EPG) values of blocked groups. Groups killed for worm recovery are indicated by shading.

\begin{tabular}{lcc}
\hline Animals by block & EPG range & EPG mean \\
\hline Block 1 & $780-360$ & 596.0 \\
Block 2 & $324-355$ & 292.0 \\
Block 3 & $245-214$ & 231.0 \\
Block 4 & $211-185$ & 200.8 \\
Block 5 & $182-173$ & 177.6 \\
Block 6 & $168-149$ & 156.3 \\
Block 7 & $147-132$ & 141.6 \\
Block 8 & $130-120$ & 123.3 \\
Block 9 & $120-110$ & 116.5 \\
Block 10 & $103-101$ & 102.0 \\
Block 11 & $101-86$ & 93.0 \\
Block 12 & $84-79$ & 81.6 \\
Block 13 & $77-67$ & 71.5 \\
Block 14 & $67-60$ & 63.0 \\
Block 15 & $60-65$ & 58.8 \\
Block 16 & $55-51$ & 53.6 \\
Block 17 & $50-41$ & 46.1 \\
Block 18 & $38-35$ & 36.2 \\
Block 19 & $34-29$ & 32.3 \\
Block 20 & $29-22$ & 25.6 \\
Block 21 & $22-19$ & 20.0 \\
Block 22 & $19-10$ & 14.0 \\
Block 23 & $10-5$ & 7.0 \\
Block 24 & $5-2$ & 3.6 \\
\hline
\end{tabular}

study in temporary wet mounts on glass microscope slides. Interference-contrast light microscopy was used to study the synlophe (pattern of surface longitudinal cuticular ridges) and other characters at a magnification of $200-$ $400 \times$. Specimens of Cooperia punctata, C. spatulata and C. oncophora were identified on the basis of spicule morphology and characteristics of the synlophe described by Lichtenfels (1977). Specimens of $H$. contortus and H. placei were identified on the basis of spicule length (Lichtenfels et al., 1988a) and morphology, and characteristics of the synlophe (Lichtenfels et al., 1994). Specimens of Nematodirus helvetianus were identified on the basis of characteristics of the spicules and synlophe (Lichtenfels and Pilitt, 1983). Ostertagia ostertagi were identified on the basis of synlophe characteristics (Lichtenfels et al., 1988b; Lichtenfels and Hoberg, 1993). The characters of the synlophe made it possible to identify males and females of all species. Fourth-stage larvae were identified to genus. The specimens have been deposited in the U.S. National Parasite Collection (Nos. 094594.00-094687.00).

\subsection{Statistical analyses}

Data were analyzed using Sigma Stat ${ }^{\mathbb{R}}$ (Point Richmond, CA). Data were analyzed for normality using the Kolmogorov-Smirnov test. Data found to be normally distributed were analyzed by one-way ANOVA and differences in the mean values among the treatment groups were compared using the Holm-Sidak method. For data not adhering to the assumption of normality, analysis was performed using the Kruskal-Wallis one-way analysis of variance on ranks, followed by pairwise comparison using Dunn's method.

\section{Results}

\subsection{Fecal egg reduction test}

The reduction in mean fecal EPG, at 14 days after treatment, for all groups tested was $<85 \%$ (Table 2 ). The highest reduction $(82 \%)$ was seen in the moxidectin group and the lowest reduction (42\%) in the eprinomectin group (Table 2). In the $\sim 3$ weeks between initial and subsequent sampling, the mean EPG in the untreated group fell by $54 \%$. Lower than expected efficacy was seen in all treatment groups, with few animals in any group showing reductions $\geq 90 \%$ (Table 2).

Table 2

Results of fecal egg reduction test. Fecal EPG values were determined approximately 1 week prior to treatment and again 14 days after treatment.

\begin{tabular}{llll}
\hline $\begin{array}{l}\text { Treatment } \\
\text { (no. of animals) }\end{array}$ & $\begin{array}{l}\text { Mean } \pm \text { SD } \\
\text { before } \\
\text { treatment }\end{array}$ & $\begin{array}{l}\text { Mean } \pm \text { SD } \\
\text { after } \\
\text { treatment }\end{array}$ & $\begin{array}{l}\text { \% reduction } \\
(\text { no } \geq 95 \%)\end{array}$ \\
\hline None (21) & $123 \pm 167^{\mathrm{a}}$ & $56 \pm 61^{\mathrm{b}}$ & $54(3)^{\mathrm{b}}$ \\
Moxidectin (20) & $107 \pm 99^{\mathrm{a}}$ & $19 \pm 25^{\mathrm{ab}}$ & $82(5)^{\mathrm{ab}}$ \\
Doramectin (21) & $121 \pm 167^{\mathrm{a}}$ & $46 \pm 55^{\mathrm{b}}$ & $62(4)^{\mathrm{b}}$ \\
Eprinomectin (20) & $111 \pm 112^{\mathrm{a}}$ & $64 \pm 58^{\mathrm{bc}}$ & $42(0)^{\mathrm{bc}}$ \\
Ivermectin (21) & $123 \pm 169^{\mathrm{a}}$ & $52 \pm 85^{\mathrm{b}}$ & $57(1)^{\mathrm{b}}$ \\
Albendazole (19) & $87 \pm 81^{\mathrm{a}}$ & $27 \pm 37^{\mathrm{ab}}$ & $69(6)^{\mathrm{b}}$ \\
\hline
\end{tabular}

The superscripts are a statistical notation indicating the degree of difference. 
Table 3

Mean number of worms recovered from necropsy performed 7 days after treatment.

\begin{tabular}{llrr}
\hline Treatment & $\begin{array}{l}\text { Mean } \\
\text { abomasum }\end{array}$ & $\begin{array}{l}\text { Mean small } \\
\text { intestine }\end{array}$ & Total \\
\hline None & $1575^{\mathrm{a}}$ & $242^{\mathrm{ab}}$ & $1,817^{\mathrm{ab}}$ \\
Moxidectin & $2442^{\mathrm{a}}$ & $5,308^{\mathrm{b}}$ & $7,750^{\mathrm{b}}$ \\
Doramectin & $1188^{\mathrm{a}}$ & $4,800^{\mathrm{b}}$ & $5,988^{\mathrm{b}}$ \\
Eprinomectin & $1868^{\mathrm{a}}$ & $3,708^{\mathrm{b}}$ & $5,576^{\mathrm{b}}$ \\
Ivermectin & $2470^{\mathrm{a}}$ & $11,875^{\mathrm{bc}}$ & $14,345^{\mathrm{bc}}$ \\
Albendazole & $1008^{\mathrm{a}}$ & $17^{\mathrm{ab}}$ & $1,025^{\mathrm{ab}}$ \\
\hline
\end{tabular}

The superscripts are a statistical notation indicating the degree of difference.

\subsection{Total worms recovered}

Upon necropsy, all treated groups contained worms. The fewest total worms were found in the albendazole group (1025), while the greatest numbers of worms were found in the ivermectin group $(14,325)$ (Table 3 ). By comparison, the untreated group harbored a mean of 1817 worms (Table 3). All groups contained similar numbers of parasites in their abomasa (1008-2470), but significant differences were seen in the number of parasites recovered from the small intestine. The smallest number of parasites was seen in the albendazole treated cattle (17), while all avermectin- and moxidectin-treated cattle harbored several thousand parasites (Table 3 ). Untreated cattle had a mean of 242 parasites in the small intestine.

\subsection{Species of parasites recovered}

The predominant species recovered from the abomasum was $H$. placei, accounting for more than half the parasites recovered in all groups (range 55-99\%). Only in the benzimidazole group did $H$. contortus account for all parasites found in the organ (Table 4 ). A very small number of $O$. ostertagi found were in the untreated group, the eprinomectin group and the albendazole group, but these accounted for $<0.5 \%$ of the total abomasal parasites for each group (data not shown).

Table 4

Species of parasites recovered from the abomasa as percent of total.

\begin{tabular}{llll}
\hline Treatment & $\begin{array}{l}\text { Mean } \\
\text { abomasum }\end{array}$ & $\begin{array}{l}\text { Haemonchus } \\
\text { placei }\end{array}$ & $\begin{array}{l}\text { Haemonchus } \\
\text { contortus }\end{array}$ \\
\hline None & 1575 & 29 & 71 \\
Moxidectin & 2442 & 33 & 67 \\
Doramectin & 1188 & 27 & 73 \\
Eprinomectin & 1868 & 45 & 55 \\
Ivermectin & 2470 & 28 & 72 \\
Albendazole & 1008 & 0 & 99 \\
\hline
\end{tabular}

Table 5

Species of parasites recovered from the small intestine as percent of total.

\begin{tabular}{lcccc}
\hline Treatment & $\begin{array}{l}\text { Mean small } \\
\text { intestine }\end{array}$ & $\begin{array}{l}\text { Cooperia } \\
\text { punctata }\end{array}$ & $\begin{array}{l}\text { Cooperia } \\
\text { oncophora }\end{array}$ & $\begin{array}{c}\text { Cooperia } \\
\text { spatulata }\end{array}$ \\
\hline None & 242 & 89 & 0 & 11 \\
Moxidectin & 5,308 & 96 & 0 & 4 \\
Doramectin & 4,800 & 86 & 10 & 3 \\
Eprinomectin & 3,708 & 85 & 2 & 13 \\
Ivermectin & 11,875 & 90 & 8 & 2 \\
Albendazole & 17 & 100 & 0 & 0 \\
\hline
\end{tabular}

The predominant species recovered from the small intestine of all groups was C. punctata (range 85-100\%), with lesser numbers of $C$. oncophora and $C$. spatulata (Table 5). As for the abomasal parasites, only in the albendazole group were $>99 \%$ of the parasites recovered identified as C. punctata (Table 5).

\section{Discussion}

The results reported here for the first time demonstrate the presence in the US of cattle parasites resistant to the avermectins, moxidectin and a benzimidazole. This is an extremely important finding given the prevailing notion that resistance to ivermectin and related compounds would be slow to arise if it appeared at all in cattle. That such resistance is widespread in small ruminants is accepted, but a segment of the American cattle producing industry has argued that the diversity of American cattle production industry would work against the selection of such resistance. This is based upon the general assumption that cattle are usually less frequently dosed than small ruminants (Waller, 1994). The argument has been that, because a significant portion of American cattle are raised in areas where environmental conditions preclude heavy parasite transmission, i.e. the arid to semi-arid West, there would not be a blanket selective pressure placed upon the parasite populations. What has been overlooked has been the high efficacy of the macrocyclic lactones and the implementation of more aggressive treatment programs aimed at increasing producer profitability by maximizing parasite control. The use of highly efficacious, long lasting drugs coupled with very effective strategic dosing regimens has convinced many producers to use the drugs more frequently. Coupled with the demonstrated success and popularity of intensive rotational grazing programs, this has resulted in more producers using more drugs in systems that are designed to better utilize forage resources. An example of this is the present case, where a "backgrounder" saw unprecedented weight gains and subsequent profits by strategic dosing of susceptible animals. This particular production system has been closely monitored for $>17$ years, and random fecal egg counts taken in the fall had routinely demonstrated very low numbers of eggs in the feces until the 2002 grazing season. The appearance of parasites resistant to all the macrocyclic lactones was noted in the short span of approximately 3 years. In addition, there have been some suggestions that resistance to avermectins would not be seen to moxidectin (a milbemycin), and that moxidectin can be used in areas of avermectin resistance (Kieran, 1994). The results of this study do not support this concept, and although moxidectin was slightly more efficacious than the avermectins, resistance is still evident. Additionally, at least one parasite species (H. placei) appears to be resistant to multiple classes of anthelmintics.

At present it appears that a North American population of $C$. punctata has been selected for resistance to all macrocyclic lactone anthelmintics including moxidectin, but that the parasite remains susceptible to benzimidazoles. A similar resistance pattern was seen in $H$. placei, in which resistance seems to be restricted to the avermectins 
and moxidectin. Conversely, $H$. contortus in this cattle population appears to be resistant to two classes of anthelmintics. Although it could be argued that this population of $H$. contortus might have originated from small ruminants, it is clear from the results of this study that parasites encountered in this study are well adapted to transmission in cattle, as the pastures under study have not seen small ruminants for $>40$ year. Whatever the original source of the parasites, there exists in the US at least several species of nematodes that are well adapted to transmission within cattle populations, and are also refractory to the most commonly used anthelmintics.

Interestingly, very few 0 . ostertagi were found in this study, even within the "untreated" group. This indicates that, at least at the location studied, Ostertagia remains susceptible to the drugs used. It also attests to the effectiveness of strategic worming programs in cleaning up pastures harboring drug-susceptible parasites. While it is comforting that the most pathogenic cattle parasite remains susceptible to commonly used drugs, the fact remains that this study was initiated because the producer noticed apparent parasitic gastroenteritis in his cattle. It is likely that the widespread use of the avermectins for $>2$ decades has altered the face of parasitic gastroenteritis in the US, and that in the future the most economically important parasite will not be Ostertagia, but rather less pathogenic forms which because of their drug resistance patterns thrive in particular production systems. This will challenge parasitologists to draw less on generalizations about parasite transmission profiles, and instead develop approaches more tailored for a given production location.

An intriguing finding in this study is the large numbers of Cooperia sp. found in the avermectin- and moxidectintreated groups compared to the untreated group. Care must be taken not to ascribe undue weight to this finding. The current results are based upon the necropsy of 3 animals per group. The differences seen in this study could be due to a sampling error, especially given the overdispersion seen in GI nematode populations in cattle (Gasbarre et al., 1990). Conversely, as mentioned above, repeated drug administration in a situation in which parasite species show different levels of susceptibility to the drugs may have altered the host-GI nematode biosystem such that alterations of nematode interspecific interactions in the gut could favor the establishment of certain species. The study present herein is being replicated and expanded. Once the results of these current studies are available, this question can be more accurately addressed.

In summary, this report documents for the first time the presence of anthelmintic resistant nematodes in cattle in the US. It is critically important to understand the extent of distribution of such parasites, to develop a strategy to limit their spread, and to identify effective alternative control programs to insure producer profitability and survival.

\section{References}

Anziani, O.S., Suarez, V., Guglielmone, A.A., Warnke, O., Grande, H., Coles, G.C., 2004. Resistance to benzimidazoles and macrocyclic lactone anthelmintics in cattle nematodes in Argentina. Vet. Parasitol. 122, 303-306.

Coles, G.C., Bauer, C., Borgsteede, F.H.M., Geerts, S., Klei, T.R., Taylor, M.A., Waller, P.J., 1992. World Association for the Advancement of Veterinary Parasitology (W.A.A.V.P.) methods for the detection of anthelmintic resistance in nematodes of veterinary importance. Vet. Parasitol. 44, 35-44.

Gasbarre, L.C., Leighton, E.A., Davies, C.J., 1990. Genetic control of immunity to gastrointestinal nematodes of cattle. Vet. Parasitol. 37, 257272 .

Hosking, B.C., Watson, T.G., Leathwick, D.M., 1996. Multigeneric resistance to oxfendazole by nematodes in cattle. Vet. Rec. 138, 67-68.

Kieran, P.J., 1994. Moxidectin against ivermectin-resistant nematodes-a global view. Aust. Vet. J. 71, 18-20.

Lichtenfels, J.R., 1977. Differences in cuticular ridges among Cooperia spp. of North American ruminants with an illustrated key to species. Proc. Helminthol. Soc. Wash. 44, 111-119.

Lichtenfels, J.R., Pilitt, P.A., 1983. Cuticular ridge patterns of Nematodirus spp. (Nematoda: Trichostrongyloidea) of North American Ruminants with a key to species. Proc. Helminthol. Soc. Wash. 50, 261-274.

Lichtenfels, J.R., Pilitt, P.A., Le Jambre, L.F., 1988a. Spicule lengths of the stomach nematodes of ruminants, Haemonchus contortus, Haemonchus placei and their hybrids. Proc. Helminthol. Soc. Wash. 55, 97-100.

Lichtenfels, J.R., Pilitt, P.A., Lancaster, M.B., 1988b. Cuticular ridge patterns of seven species of Ostertagiinae (Nematoda) parasitic in domestic ruminants. Proc. Helminthol. Soc. Wash. 55, 77-86.

Lichtenfels, J.R., Hoberg, E.P., 1993. The systematics of nematodes that cause Ostertagiasis in domestic and wild ruminants in North America with a key to species. Vet. Parasitol. 46, 33-53.

Lichtenfels, J.R., Pilitt, P.A., Hoberg, E.P., 1994. New morphological characters for identifying individual specimens of Haemonchus spp. (Nematoda; Trichostrongyloidea) and a key to species in ruminants of North America. J. Parasitol. 80, 107-119.

Stafford, K., Coles, G.C., 1999. Nematode control practices and anthelmintic resistance in dairy calves in the southwest of England. Vet. Rec. 144, 659-661.

Vermunt, J.J., West, D.M., Pomroy, W.E., 1995. Multiple resistances to ivermectin and oxfendazole in Cooperia species of cattle in New Zealand. Vet. Rec. 137, 43-45.

Waller, P.J., 1994. The development of anthelmintic resistance in ruminant livestock. Acta Trop. 56, 233-243.

Waller, P.J., 1997. Anthelmintic resistance. Vet. Parasitol. 72, 391-412. 